\title{
CMEARTICLE
}

\section{Management of scabies}

Farhad Fakhrudin $\underline{\text { Vasanwala }}^{1,2}$, FRCP, FCFP, Chong Yau $\underline{\text { Ong }}^{3}$, MRCP, FCFP, Chen Wee Derrick $\underline{A w}^{4}$, MRCP, FAMS, Choon How $\underline{\mathrm{How}}^{2,5,6}$, FCFP, FAMS

\begin{abstract}
Mdm Lee, who was alert and communicative, was wheeled into your consultation room for follow-up of hypertension. She had come from a nursing home and was accompanied by her daughter and a nurse from the home. While manually checking her blood pressure, you noticed that Mdm Lee was scratching incessantly. You examined her and noted numerous excoriated erythematous papules on the hands (palms and fingers), wrists, external genitalia and axillae. Mdm Lee said that she had felt increasingly itchy over the past week and had difficulty sleeping at night despite taking loratadine once daily. No new chronic medication had been prescribed to her in the past six months, according to the daughter and nurse. On questioning, the nurse said that none of the patients or staff in the ward had a similar rash. You made a provisional diagnosis of classic scabies and considered your next steps.
\end{abstract}

\section{HOW COMMON IS THIS IN MY PRACTICE?}

Scabies is a common infection affecting individuals of any age and socioeconomic status. The worldwide prevalence is estimated to be 100 million people. ${ }^{(1)}$ Lim et al conducted a review of 114 patients who were treated for scabies at the National Skin Centre in 1982-1989.(2) The data showed that with increased modernisation in Singapore, the prevalence of scabies was higher in institutions such as intermediate and long-term care facilities rather than in residential homes. The authors postulated that this was because of improvements in housing facilities, resulting in less crowding. With the increase in travel and humanitarian work by our local population, particularly in developing countries, the risk of contracting scabies from people living in compromised housing has correspondingly increased..$^{(3)}$

\section{Clinical manifestations}

The two major clinical variants of scabies are classic scabies and crusted scabies. Symptoms typically appear 2-6 weeks after infestation. Classic scabies (Fig. 1), the most common presentation, is associated with a relatively low mite burden of approximately 10-15 mites on the body. Crusted scabies (Fig. 2), on the other hand, usually occurs in older or immunocompromised individuals and is associated with a higher mite burden (up to millions of mites on the body). ${ }^{(4)}$ It is also more often seen in disabled and institutionalised patients. This infestation often presents as generalised dermatitis with crusted hyperkeratoses on the palms, soles, under the fingernails, and on the ears, trunks and extremities. Pruritus may be minimal or absent, or the host may be physically incapable of scratching. ${ }^{(5)}$

The salient features of classic scabies are intense itch, erythematous papules and excoriations, typical distribution, and a contact history of patients with scabies. The usual distribution is: the interdigital web space of the fingers, the insides of wrists and on the inner elbow; the soles of the feet; around the breasts and axillae; the male genitalia, especially the scrotal and penile areas; and on the buttocks, knees and shoulder blades. ${ }^{(6)}$ In children, common sites of infestation are the scalp, face and neck, and palms and soles.

\section{WHAT CAN I DO IN MY PRACTICE? Making the diagnosis}

The combination of visual inspection, noting the characteristic pruritic lesions and their distribution, together with contact history enables the primary care practitioners to make a confident diagnosis of scabies. Differential diagnoses include other pruritic conditions such as drug eruptions, eczema, lichen planus and other infestations such as hemiptera (bedbugs). Apart from the symptomatology, other salient points in history-taking include a detailed drug history. Eczema may present at the flexures, while classical lichen planus tends to affect the volar aspects of wrists and ankles as well as the anterior aspects of the knees. As for scabies, areas affected include the interdigital web space of the fingers and the sides of the hands. The wrists, elbows, axillae, groin, breasts and feet are the other commonly affected sites (Fig. 3). A skin scrape can be taken at non-excoriated areas or noninflamed areas where there are burrows and a pimple-like rash.

\footnotetext{
${ }^{1}$ Medical Care Services, Institute of Mental Health, ${ }^{2}$ Family Medicine Academic Clinical Programme, SingHealth Duke-NUS Academic Medical Centre, ${ }^{3}$ Department of Post-Acute and Continuity Care, Sengkang Community Hospital, ${ }^{4}$ Department of General Medicine, Sengkang General Hospital, ${ }^{5}$ Care and Health Integration, Changi General Hospital, ${ }^{6}$ SingHealth Polyclinics, Singapore

Correspondence: Dr How Choon How, Head of Division, Consultant, Care and Health Integration, Changi General Hospital, 2 Simei Street 3 , Singapore 529889. how.choon.how@singhealth.com.sg
} 

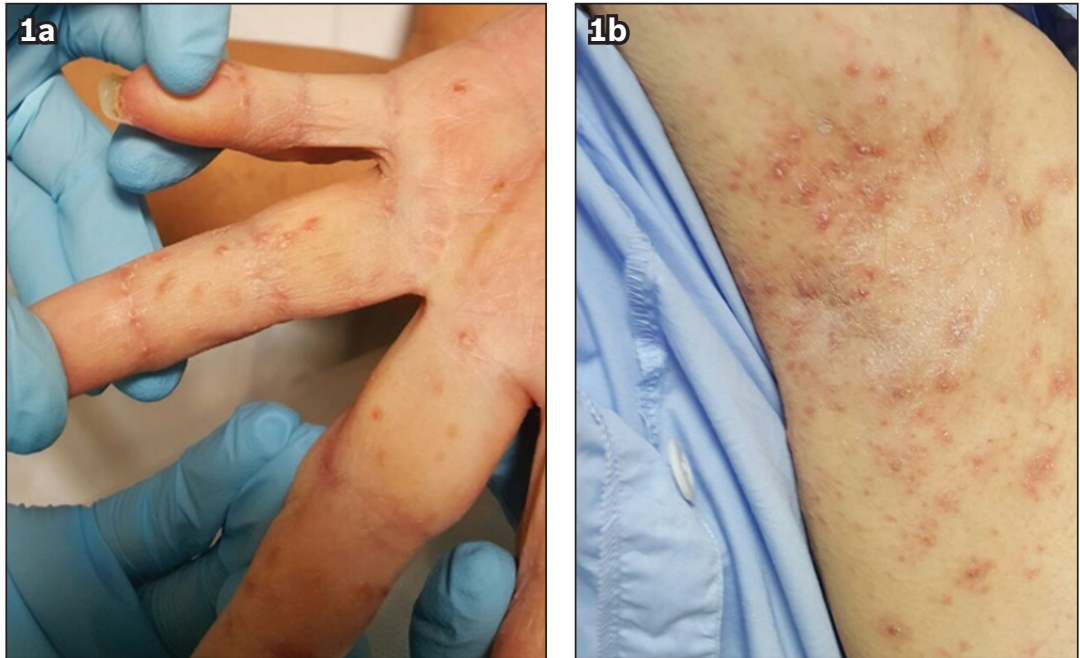

Fig. 1 Photograph shows numerous erythematous papules on (a) the fingers and web spaces and (b) axilla of a patient with classic scabies

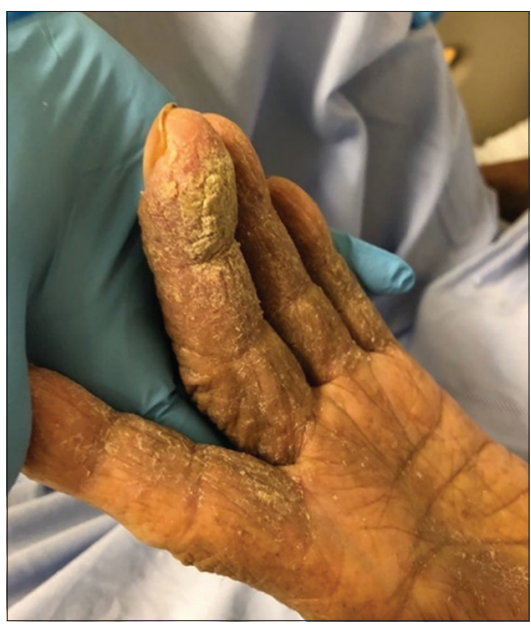

Fig. 2 Photograph shows hyperkeratotic crusts on the fingers and palms in a nursing home patient with crusted scabies.

\section{Box 1. Principles of treatment in household, community and} institution facilities:

1. Isolate the patient until the completion of treatment (Table I).

2. Clean the patient's room thoroughly.

3. Avoid direct skin-to-skin contact (using protective garments, e.g. gowns and gloves) and implement strict handwashing.

4. The patient's bedding and clothing should be machine-laundered separately using hot water of above $75^{\circ} \mathrm{C}$, followed by hot dryer cycles.

5. Prophylactic topical malathion $0.5 \%$ lotion should be prescribed to all household contacts or healthcare workers caring for the patient.

\section{Early recognition and treatment}

When asking a patient about number of household members, physicians are reminded to specifically ask if there were domestic helpers or grandparents living together or staying intermittently up to six weeks prior to the presentation. Patient and family members should be informed that although scabies infestation is relatively benign, it is highly transmissible. Therefore, the principles of treatment (Box 1) should be carried out diligently. Table I shows the treatment regime for each patient group..$^{(7,8)}$

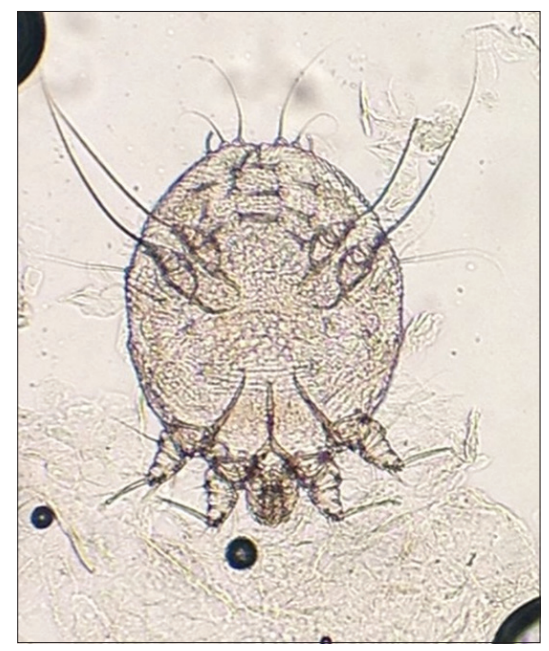

Fig. 3 Photomicrograph of an adult Sarcoptes scabiei.

In nursing homes and institutions, early recognition of crusted scabies is essential to prevent outbreaks. ${ }^{(9)}$ Once an outbreak occurs, prompt control of the index patient and rapid tracing of contacts to identify secondary cases are necessary. When prolonged exposure to a case of crusted scabies results in multiple secondary cases, the most efficient strategy for terminating the outbreak is the institution of simultaneous mass prophylaxis, which can be implemented without ward closure.

It is important to recognise that itching may persist or even worsen for some time after applying the medication. These steps may give patients some relief from itching:(10)

1. Cool and soak the skin by using a cool, wet washcloth on irritated areas of the skin.

2. Apply a soothing lotion such as calamine lotion.

3. If the itching is severe, consider antihistamines to relieve the itching and skin irritation. Non-sedative antihistamines appear to be as effective as sedating histamines.

4. After eradication of mites, medium-potency topical corticosteroids (in age-appropriate patients) can also be used to control itching for 1-2 weeks, especially for scabetic nodules. ${ }^{(5)}$ 
Table I. Medical treatment for scabies. ${ }^{(7,8)}$

\begin{tabular}{|c|c|c|}
\hline Category & Medication & Instructions \\
\hline \multirow{2}{*}{$\begin{array}{l}\text { Adults and children } \\
\text { aged } 6 \text { months and } \\
\text { above }\end{array}$} & $\begin{array}{l}\text { Topical permethrin } 5 \% \text { lotion } \\
\text { OR }\end{array}$ & $\begin{array}{l}\text { Apply on the entire body from neck down. Wash off after 8-14 hours. } \\
\text { To repeat in } 1 \text { week. }\end{array}$ \\
\hline & Topical malathion $0.5 \%$ lotion & $\begin{array}{l}\text { Apply on the entire body from neck down. Wash off after } 24 \text { hours. To } \\
\text { repeat in } 1 \text { week to kill any mites emerging from eggs that survived } \\
\text { the first application. }\end{array}$ \\
\hline \multirow[t]{3}{*}{$\begin{array}{l}\text { Infants aged more } \\
\text { than } 2 \text { months and } \\
\text { less than } 6 \text { months* }^{*}\end{array}$} & $\begin{array}{l}\text { 1st line: } \\
\text { Topical permethrin } 5 \% \text { lotion }\end{array}$ & $\begin{array}{l}\text { Apply on the entire body from neck down. Wash off after 8-14 hours. } \\
\text { To repeat in } 1 \text { week. }\end{array}$ \\
\hline & 2nd line: & \\
\hline & $\begin{array}{l}\text { Refer to National Skin Centre for } 6 \% \\
\text { sulphur in petrolatum }\end{array}$ & $\begin{array}{l}\text { Apply before bedtime and wash off the following morning. Repeat for } \\
5 \text { days. }\end{array}$ \\
\hline $\begin{array}{l}\text { Infants aged } 2 \text { months } \\
\text { and below* }\end{array}$ & $\begin{array}{l}\text { Refer the patient to National Skin } \\
\text { Center for } 6 \% \text { sulphur in petrolatum }\end{array}$ & $\begin{array}{l}\text { Apply before bedtime and wash off the following morning. Repeat for } \\
5 \text { days. }\end{array}$ \\
\hline \multirow[t]{4}{*}{ Pregnancy } & $\begin{array}{l}\text { 1st line (as for adults): } \\
\text { Topical permethrin } 5 \% \text { lotion } \\
\text { OR }\end{array}$ & $\begin{array}{l}\text { Apply on the entire body from neck down. Wash off after 8-14 hours. } \\
\text { To repeat in } 1 \text { week. }\end{array}$ \\
\hline & Topical malathion $0.5 \%$ lotion & $\begin{array}{l}\text { Apply on the entire body from neck down. Wash off after } 24 \text { hours. To } \\
\text { repeat in } 1 \text { week to kill any mites emerging from eggs that survived } \\
\text { the first application. }\end{array}$ \\
\hline & 2nd line: & \\
\hline & $\begin{array}{l}\text { Refer the patient to National Skin } \\
\text { Center for } 6 \% \text { sulphur in petrolatum }\end{array}$ & $\begin{array}{l}\text { Apply before bedtime and wash off the following morning. Repeat for } \\
5 \text { days. }\end{array}$ \\
\hline \multirow[t]{2}{*}{ Crusted scabies* } & $\begin{array}{l}\text { Topical permethrin } 5 \% \text { lotion } \\
\text { AND }\end{array}$ & $\begin{array}{l}\text { Apply on the entire body from neck down. Wash off after 8-14 hours. } \\
\text { To repeat in } 1 \text { week. }\end{array}$ \\
\hline & $\begin{array}{l}\text { Oral ivermectin } 2 \text { doses }(200 \mu \mathrm{g} / \mathrm{kg} / \\
\text { dose) } 1 \text { week apart }\end{array}$ & $\begin{array}{l}\text { Oral ivermectin should be taken with food. Patients should be } \\
\text { reviewed after completion of the } 2 \text { nd dose. }\end{array}$ \\
\hline
\end{tabular}

*Dermatology consult is advisable.

Scabies may result in secondary skin infections leading to boils, cellulitis or lymphangitis due to Streptococcus pyogenes (S. pyogenes). Streptococci and staphylococci have been isolated from skin burrows as well as mite faecal pellets, suggesting that the mites themselves may contribute to the spread of pathogenic bacteria. ${ }^{(11)}$ Secondary infection of scabies with $S$. pyogenes is a major precipitant of acute post-streptococcal glomerulonephritis and possibly rheumatic fever. ${ }^{(12)}$

\section{TAKE HOME MESSAGES}

1. Scabies is a common infestation affecting individuals of any age and socioeconomic status.

2. In Singapore, scabies is more common in institutions than at home.

3. All household contacts of the patient need to be prophylactically treated and practise contact precautions.

4. Once an outbreak occurs, prompt control of the index patient and rapid tracing of contacts to identify secondary cases are necessary.

5. For adults, treatment for scabies comprises of two applications of topical malathion $0.5 \%$ or permethrin $5 \%$, spaced one week apart.

6. For adults, the prophylaxis of scabies also comprises of two applications of topical malathion $0.5 \%$, spaced one week apart, preferably both on the same days as the patient's treatment.

7. It is advisable to refer patients with suspected crusted scabies to the dermatologist for further evaluation and management.

You treated Mdm Lee for suspected classic scabies and instituted contact precautions immediately. She was nursed in an isolation cubicle inside the nursing home. The chief nurse and management were informed of the outbreak. Mdm Lee's linen, surroundings and bed were thoroughly washed and disinfected. Mdm Lee, along with the patients in the same cubicle and the nurses attending to her, were given two courses of malathion $0.5 \%$ lotion one week apart. Her daughter was also treated with an application of malathion $0.5 \%$ lotion one week apart, as she had been in close contact with her mother during her visits to the nursing home. By the end of the second week, $\mathrm{Mdm}$ Lee was feeling better and had no further evidence of scabies. No new cases of scabies were reported in the nursing home. 
ABSTRACT Scabies is a common infestation worldwide, affecting persons of any age and socioeconomic status. In Singapore, it is more common in institutions rather than in homes. The two variants are classic scabies and crusted scabies, with the latter having a significantly higher mite burden. Early identification, isolation of index patients and prophylactic treatment of contacts are essential in dealing with the outbreak. Locally, most primary care practitioners make the diagnosis based on visual inspection and clinical examination. A skin scrape is done to confirm the diagnosis, especially in atypical presentations. Scabietic mites, eggs or faeces can be seen on microscopy. The usual treatment for adult scabies in Singapore is the use of topical malathion or permethrin. A combination of topical permethrin and oral ivermectin is used for crusted scabies.

Keywords: mites, sarcoptes, scabies

\section{REFERENCES}

1. Fuller LC. Epidemiology of scabies. Curr Opin Infect Dis 2013; 26:123-6.

2. Lim JT, Thirumoorthy T. The changing patterns of scabies among in-patients in
Singapore (1982-1989). Singapore Med J 1991; 32:121-2.

3. Késmárszky R, Jakkel A, Szabó G. Dermatological aspects of a humanitarian mission. J Allergy Ther 2016; 7:228.

4. Goldstein BG, Goldstein AO. Scabies: epidemiology, clinical features, and diagnosis. Available at: https://www.uptodate.com/contents/scabiesepidemiology-clinical-features-and-diagnosis. Accessed May 2, 2019.

5. Ministry of Health, Malaysia. Guideline for management of scabies in adults and children. February 2015. Available at: http://www.moh. gov.my/ index.php/file manager/dl_item/ 5232467961584d67554746 755a485668626942515a5735355957 74706443394864576c6b5a577 $870626 d 5567526$ d397949453168626d466e5a57 316c626e51675432 $596755324 \mathrm{e} 68596 \mathrm{~d} 6 \mathrm{c} 6 \mathrm{c} 6379424 \mathrm{a} 62 \quad 6942425 \mathrm{a} 48567364484 \mathrm{~d} 67$ 5157356b49454e6f61577 86b636d56754c6e426b 5a673d3d. Accessed May 2, 2019

6. Usatine RP, Smith MA, Mayeaux EJR, Chumley H. The colour atlas of family medicine. 1st ed. New York; McGraw-Hill Education, 2008: 575-80.

7. Centers for Disease Control and Prevention. Scabies. Available at: https://www. cdc.gov/parasites/scabies/index.html. Accessed May 2, 2019.

8. SingHealth. Scabies Medication -Available at: https://www.singhealth.com.sg/ patient-care/medicine/scabies/dosage. Accessed May 2, 2019.

9. Khan A, O'Grady S, Muller MP. Rapid control of a scabies outbreak at a tertiary care hospital without ward closure. Am J Infect Control 2012; 40:451-5.

10. Baldwin A, Hjelde N, Goumalatsou C, Myers C, eds. Oxford Handbook of Clinical Specialties. $10^{\text {th }}$ Edition. Oxford: Oxford University Press, 2016: 608 .

11. Currie BJ, Carapetis JR. Skin infections and infestations in Aboriginal communities in northern Australia. Australas J Dermatol 2000; 41:139-43.

12. Hersch C. Acute glomerulonephritis due to skin disease, with special reference to scabies. S Afr Med J 1967; 41:29-34. 


\section{SINGAPORE MEDICAL COUNCIL CATEGORY 3B CME PROGRAMME} (Code SMJ 201906A)

1. Scabies is a common infection affecting young individuals and people of lower socioeconomic status.

2. The incidence of scabies in Singapore is approximately equal among residents in institutions and those staying in their own homes.

3. There are three major clinical variants of scabies: classic scabies, crusted scabies and Norwegian scabies.

4. Scabies symptoms appear 2-6 weeks after infestation.

5. The number of mites on the body in classic scabies is more than a thousand times that of crusted scabies.

6. Crusted scabies usually occurs in older adults or immunocompromised individuals.

7. Classic scabies infestations often present as generalised dermatitis with crusted hyperkeratoses on the palms, soles, under the fingernails, and on the ears, trunk and extremities.

8. Salient features of classic scabies are intense itch, erythematous papules and excoriations.

9. Skin scraping, with the positive finding of mites, is necessary to diagnose scabies infestation.

10. Differential diagnoses of scabies infestation include eczema, hemiptera (bedbug) infestation, other arthropod reactions, lichen planus and drug eruptions.

11. Skin scrapings from the non-excoriated or non-inflamed areas, where there are burrows and a pimplelike rash, are more likely to yield mites.

12. Once an outbreak occurs, prompt control of the index patient and rapid tracing of contacts to identify secondary cases are necessary.

13. Topical malathion treatment of all close personal contacts should be done to avoid a cycle of transmission.

14. When identifying close personal contacts of scabies patients, do not include domestic helpers or grandparents who are living together with them.

15. When prolonged exposure to a case of crusted scabies results in multiple secondary cases in a nursing home, simultaneous mass topical treatment is the most efficient strategy for terminating the outbreak and can be implemented without ward closure.

16. The recommended treatment for classic scabies in children aged less than six months is malathion $0.5 \%$ lotion applied to all areas of the body from the neck down and left for 24 hours before washing off.

17. Itching may persist or even worsen for some time after applying the medication and topical calamine lotion or oral antihistamines and medium-potency topical steroids are recommended for scabetic nodules.

18. Scabies can cause secondary skin infections leading to boils, cellulitis or lymphangitis due to Streptococcal pyogenes. These infections are a major precipitant of acute post-streptococcal glomerulonephritis and possibly rheumatic fever.

19. When malathion $0.5 \%$ or permethrin $5 \%$ is used, treatment should be repeated in one week to kill any mites emerging from eggs that survived the first application.

20. Patients with crusted scabies should be referred to a dermatologist for assessment and appropriate management.

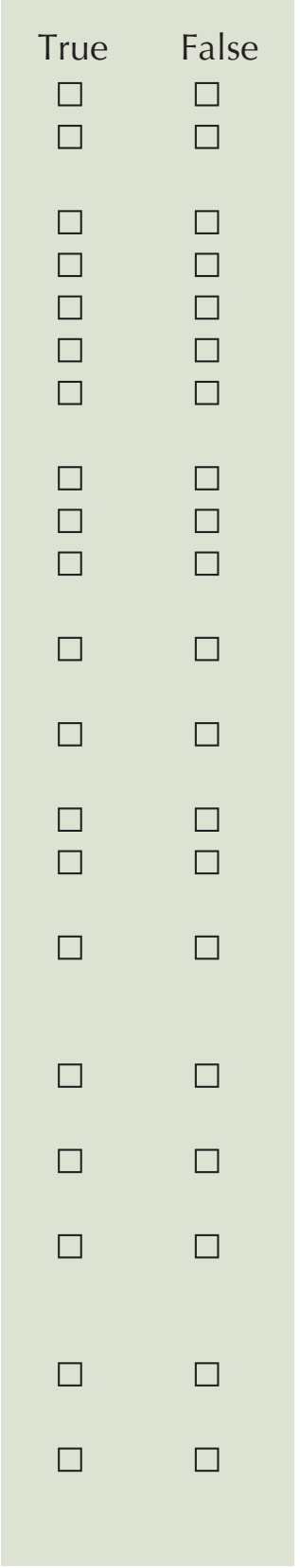

\section{Doctor's particulars:}

Name in full:

MCR no.:

Specialty:

Email:

\section{SUBMISSION INSTRUCTIONS:}

Visit the SMJ website: http://www.smj.org.sg/current-issue and select the appropriate quiz. You will be redirected to the SMA login page.

For SMA member: (1) Log in with your username and password (if you do not know your password, please click on 'Forgot your password?'). (2) Select your answers for each quiz and click 'Submit'.

For non-SMA member: (1) Create an SMJ CME account, or log in with your SMJ CME username and password (for returning users). (2) Make payment of SGD 21.40 (inclusive of $7 \%$ GST) via PayPal to access this month's quizzes. (3) Select your answers for each quiz and click 'Submit'.

RESULTS:

(1) Answers will be published online in the SMJ August 2019 issue. (2) The MCR numbers of successful candidates will be posted online at the SMJ website by 8 August 2019. (3) Passing mark is $60 \%$. No mark will be deducted for incorrect answers. (4) The SMJ editorial office will submit the list of successful candidates to the Singapore Medical Council. (5) One CME point is awarded for successful candidates. (6) SMC credits CME points according to the month of publication of the CME article (i.e. points awarded for a quiz published in the December 2017 issue will be credited for the month of December 2017, even if the deadline is in January 2018).

Deadline for submission (June 2019 SMJ 3B CME programme): 12 noon, 1 August 2019. 